\title{
Solid-phase extraction for RP-HPLC/UV determination of ziprasidone at presence its main metabolite in urine
}

\author{
Sophia Davydovych $^{1 *}$, Iryna Halkevych ${ }^{1}$, Olha Korobova $^{2}$, Svitlana Humenyuk $^{1}$ \\ ${ }^{1}$ Department of Toxicological and Analytical Chemistry, Danylo Halytsky Lviv National Medical University; Pekarska str., 69, Lviv, Ukraine \\ ${ }^{2}$ Laboratory of HPLC, State Scientific Research Control Institute of Veterinary Medicinal Products and Feed Additives, 11, Donetska str., Lviv, Ukraine.
}

\begin{tabular}{|c|c|}
\hline ARTICLE INFO & ABSTRACT \\
\hline $\begin{array}{l}\text { Article history: } \\
\text { Received on: } 21 / 02 / 2017 \\
\text { Accepted on: } 30 / 03 / 2017 \\
\text { Available online: } 30 / 05 / 2017\end{array}$ & $\begin{array}{l}\text { The rapid and accurate high-performance liquid chromatography method with ultraviolet detection }(210 \mathrm{~nm}) \text { for } \\
\text { the determination of Ziprasidone in rat urine was developed. Simple protocol of solid-phase extraction of } \\
\text { ziprasidone from urine sample at presence its main metabolites was worked out. Vardenafil was used as an } \\
\text { internal standard. Reversed phase column LUNA }{ }^{\circ} \text { C18(2) } 100 \mathrm{~A} 250 \mathrm{~mm} \times 4.6 \mathrm{~mm} \times 5 \mu \mathrm{m} \text { was used with an }\end{array}$ \\
\hline $\begin{array}{l}\text { Key words: } \\
\text { Ziprasidone, Solid-phase } \\
\text { extraction, HPLC, UV- } \\
\text { spectroscopy. }\end{array}$ & $\begin{array}{l}\text { 2.5). Developed conditions of HPLC analysis provide high efficiency of a system and good separation of } \\
\text { analytes. The method was validated and applied to rat urine samples after modelling intoxication. The intra- and } \\
\text { inter-day precision was } \leq 15 \% \text { with recovery about } 95 \% \text {. A linear range of } 1 \mu \mathrm{g} / \mathrm{mL} \text { to } 200 \mu \mathrm{g} / \mathrm{mL} \text { was } \\
\text { established. LOD and LOQ were } 0.2 \text { and } 0.5 \mu \mathrm{g} / \mathrm{mL} \text {, respectively. Obtained results indicate that the described } \\
\text { procedure of sample pretreatment with automatization possibility allows obtaining good results for ziprasidone. } \\
\text { This method is sensitive, precise and repeatable enough to be used in toxicological casework. }\end{array}$ \\
\hline
\end{tabular}

\section{INTRODUCTION}

Ziprasidone, (5-[2-[4-(1.2-benzisothiazol-3-yl)-1piperazinyl]ethyl]-6-chloro-1.3-dihydro-2H-indol-2-one) is widely used for the treatment of both positive and negative symptoms of schizophrenia (Shin et al., 2011; Strom et al., 2011;Pfizer Inc., 2014). Ziprasidone is a representative of atypical antipsychotic drugs with a unique receptor profile and ability to inhibit the reuptake of serotonin and norepinephrine. The interaction with the 5- $\mathrm{HT}_{2 \mathrm{~A}}$ and $5-\mathrm{HT}_{1 \mathrm{~A}}, 5-\mathrm{HT}_{2 \mathrm{c}}, 5-\mathrm{HT}_{1 \mathrm{D}}, 5-$ $\mathrm{HT}_{7}$ receptors and type $2\left(\mathrm{D}_{2}\right)$ dopamine receptors ziprasidonehas antipsychotic, antidepressant and anxiolytic effects (Asif, 2016). The recommended dose for the treatment of acute conditions is

* Corresponding Author

Sophia Davydovych, Department of Toxicological and Analytical Chemistry, Danylo Halytsky Lviv National Medical University; Pekarska str., 69, Lviv 79010, Ukraine. Email: ihlitska.sophia @ gmail.com
40-80 mg twice daily (Pfizer, 2014). In the case of overdose or combining it with drugs, which cause prolongation of the QT interval, the cardiotoxic effect of the drug is observed (WenzelSeifert et al., 2011; Timour et al., 2012; Beach et al., 2013; Leonard et al., 2013; Hasnain and Vieweg, 2014). Cardiovascular toxicity is the most frequent cause ofspecified or sudden cardiac death in patients with schizophrenia (Marano et al., 2011; Söderberg et al., 2016).

Ziprasidoneis intensively metabolized by CYP3A4 and aldehyde oxidase - about $5 \%$ of the dose of the drug is excreted in the urine $(<1 \%)$ and faeces $(<4 \%)$ unchanged (Levine and Ruha., 2012). The major circulating metabolites of ziprasidoneare Smethyl-dihydroziprasidone, ziprasidone sulfoxide, benzisothiazole piperazine (BITP) sulfoxide and BITP sulfone. (Xie, 2014). Smethyl-dihydroziprasidone and ziprasidone sulfoxide in tests in vitro reveal properties that may indicate the action that extends the QT interval, so determining their content in biomaterial has toxicological significance as well (Pfizer Inc., 2000). 
Several authors describe techniques for determining the presence of ziprasidone in biological material (plasma, serum, brain) using LC/MS, HPLC/MS, HPLC/UV, HPLC with fluorescence detector, UPLC/UVand the potentiometric method (García et al., 2011; Mercolini et al., 2011; Marghade et al., 2012; Sampedro et al., 2012; Sreedasyam et al., 2012; Rao et al., 2013; Mercolini et al., 2014; Sistik, 2016; Wang and Li, 2017). Preparation and analysis of samples in the described techniques were carried out in several steps and were generally timeconsuming. Elimination time of ziprasidone is short and concentrations of analytes and their metabolites in urine can be higher than in blood after few hours of ingestion. Therefore, urine and hair samples are better biosamples because drugs can be detected even days or up to weeks after the intake and, undoubtedly, the urine screening may give better results (Scott, 2009). Unfortunately, there are no described methods of isolation and identification of ziprasidone from urine samples that would be suitable for the purpose of post-mortem toxicological investigation. Summing up these factors, the relevance of this study is due to the need to develop a simple, rapid, accurate, and sensitive technique for sample preparation to detect ziprasidone in urine using the HPLC/UV. The objective of our study is elaborating conditions for identification and quantification of ziprasidone by HPLC with UV detection in samples obtained during purification of extracts from urine by solid phase extraction.

\section{MATERIALS AND METHODS}

\section{Chemicals and Reagents}

A standard sample of ziprasidone $(\geq 98.0 \%$ SigmaAldrich, USA) was used to produce a series of stock solutions, as internal standard - Vardenafil ( $\geq 98.0 \%$ Sigma-Aldrich, USA). Methanol, acetonitrile and phosphoric acid, all "HPLC" grade ( $\geq$ 99.9\%, Sigma-Aldrich, USA) wereused to prepare mobile phase, and triethylamine (for HPLC, $\geq 99.5 \%$, Fluka). All other chemicals were of analytical grade. Double distilled water obtained in MilliQ purification system (Millipore; Vienna, Austria) was used to preparetriethylamine and calcium chloride solutions. Test animals were injected with the content of Zeldox capsules (Pfizer Laboratories pvt. ltd.) containing $40 \mathrm{mg}$ of ziprasidone.

\section{Instrumentation and Chromatographic conditions}

Preparationof urine samples for the analysis was performed using Strata-X $30 \mathrm{mg}$ cartridges (Phenomenex).

Identification and quantification of ziprasidone were performed with liquid chromatograph Thermo Dionex ultimate 3000 UHPLC. The system consists of an UltiMate 3000 RS pump, an UltiMate $3000 \mathrm{RS}$ autosampler and an UltiMate $3000 \mathrm{RS}$ column compartment (Dionex, Olten/Switzerland).

Chromatographic separation of analyte was performed with a reverse phase column LUNA® C18(2) 100 Ä $250 \mathrm{~mm} \times 4.6$ $\mathrm{mm} \times 5 \mu \mathrm{m}$, at $25^{\circ} \mathrm{C}$. The composition of the mobile phase: acetonitrile- $0.5 \%$ triethylamine (30:70), $\mathrm{pH} 3.0$. The acidic $\mathrm{pH}$ was adjusted $0.1 \mathrm{M}$ phosphoric acid. The isocratic flow rate of the mobile phase was $1 \mathrm{ml} / \mathrm{min}$. The volume of injected sample was $10 \mu \mathrm{l}$. Spectrum of ziprasidone was recorded in range $190-350$ $\mathrm{nm}$. Detection was performed with LED UV detector (UV-VISDAD, FLD) at $210 \mathrm{~nm}$. The results were processed with Chromeleon $^{\circledR}$ Chromatography Data System software (Version 7.2.0.3765, Thermo Fisher Scientific). Organic solvents were evaporated with A TurboVap evaporator (Zymark; Hopkinton, MA). Urine samples were centrifuged in Sigma 3-16 KL centrifuge with cooling. Filtration of the mobile phase and samples before the injection into chromatograph was performed using PTFE membrane syringe filters with diameter of $13 \mathrm{~mm}$ and a pore size of 0.2 microns by STL-labortechnics (Czech Republic).

\section{Preparations of standard and sample solutions}

Primary standard solutions of ziprasidone and vardenafil (internal standard) were prepared separately by dissolving an accurately weighed amount of standard substances $(25 \mathrm{mg})$ with methanol in $25 \mathrm{ml}$ volumetric flask to get the final concentration of $1 \mathrm{mg} / \mathrm{ml}$. All standard solutions were stored at $4{ }^{\circ} \mathrm{C}$ in the dark place for 30 days. Stock solution of ziprasidone were obtained by diluting $5 \mathrm{ml}$ of the respective standard solutions with $20 \mathrm{ml}$ ofthe solvent (methanol) to obtain the concentrations $200 \mu \mathrm{g} / \mathrm{ml}$. Stock solutions of vardenafil $(50 \mu \mathrm{g} / \mathrm{ml})$ were prepared by diluting $1.25 \mathrm{ml}$ of appropriate standard solution with methanol in $25 \mathrm{ml}$ volumetric flask.

Three parallel series of model samples of urine with ziprasidone concentration of 1.0 to $200.0 \mu \mathrm{g} / \mathrm{ml}(1.0 ; 5.0 ; 10.0$; $20.0 ; 30.0,100.0,150.0$ and $200.0 \mu \mathrm{g} / \mathrm{ml}$ ) were prepared for the analysis. $2 \mathrm{ml}$ of pure rats' urine were spiked with $100 \mu \mathrm{l}$ of internal standard stock solution and with 10.0, 50.0, 100.0, 200.0, $300.0 \mu \mathrm{l}$ of stock solutions of ziprasidone; 200.0, 300.0, $400.0 \mu \mathrm{l}$ of standard solutions. Samples were kept for 3 minutes in the orbital mixer of "Vortex" type and then incubated at $37^{\circ} \mathrm{C}$ for 60 minutes. The resulting solutions were used to construct the calibration curve by the method of internal standard in the concentration range of $1-30 \mu \mathrm{g} / \mathrm{ml}$ and $30-200 \mu \mathrm{g} / \mathrm{ml}$. Similarly, quality control samples were prepared for method validation (QC) - pure rats' urine was spiked with ziprasidone to obtain concentrations of 5, 100 and $200 \mu \mathrm{g} / \mathrm{ml}$. Model samples and quality control samples were subject further sample preparation by the approach described below.

\section{Sample collections}

To conduct the experimental study a group of twelve white rats (230-240 g) aged 2-3 months was used. Half of them was the study group, the other half was the control one. Adult rats were obtained from the Laboratory Animal Center (Vivarium) at Danylo Halytsky Lviv National Medical University.Experiments adhered to ethical standards and approved by the ethical committee of mentioned university (Approval File No. 1/2015).The animals were kept under a $12 \mathrm{~h}$ light-dark cycle with free access to food. Animals in the study group received 
ziprasidone $(174 \mathrm{mg} / \mathrm{kg})$ in three divided doses during the day. The drug was administered intragastrically in the form of an aqueous suspension $(667 \mu \mathrm{g} / \mathrm{ml}$ in $6 \mathrm{ml})$ with the addition of Tween-80 as stabilizing agent. The choice of dose to model poisoning was resulting from the literature data (Lee et al., 2013; Hovda et al., 2016). Control animals received the same amount of solvent (water). The collection of daily urine for the analysis was performed from the first injection. The biological material was stored at $-20^{\circ} \mathrm{C}$.

\section{Sample preparation}

$2 \mathrm{ml}$ of rats' urinewere spiked with $100 \mu \mathrm{l}$ of internal standard solution $(50 \mu \mathrm{g} / \mathrm{ml})$ and $0.2 \mathrm{ml}$ of $20 \%$ solution of calcium chloride was added to precipitate of uric acid salts, and centrifuged for $15 \mathrm{~min}(5000 \times \mathrm{g})$. The supernatant was quantitatively selected and passed through a solid phase extraction cartridges Strata-X (30 mg; Phenomenex, UK). The cartridges were activated with $1 \mathrm{ml}$ of methanol and $1 \mathrm{ml}$ of distilled water before using. After the sample displacement, the columns were washed sequentially on $1 \mathrm{ml}$ of phosphate buffer $(\mathrm{pH} 7.8)$ and distilled water with the flow rate of all liquids through the cartridge $1 \mathrm{ml} / \mathrm{min}$. Ziprasidone was eluted with $2 \mathrm{ml}$ of methanol after drying the sorbent in a stream of nitrogen for 5 minutes. The volume of the solution was adjusted to $5 \mathrm{ml}$ of methanol. $1 \mathrm{ml}$ of this solution was evaporated to $500 \mu \mathrm{l}$ of methanol and $10 \mu \mathrm{l}$ of the resulting solution was injected into the chromatograph.In case quantification of ziprasidone at therapeutic doses, we recommend to elute analyte from SPE cartridges with $2 \mathrm{ml}$ methanol, evaporate it to $500 \mu \mathrm{l}$ of methanol and injected $10 \mu \mathrm{l}$ of the resulting solution into the chromatographic system. This allows to concentrate the sample in five times and to increase the limit of ziprasidone determination in biological material at the level of $125 \mathrm{ng}$ in $1 \mathrm{ml}$ of urine. Samples were mixed using a shaker of "Vortex" type for 2 minutes and filtered through membrane filters PTFE $0.2 \mu \mathrm{m}$. Control urine samples were studied in parallel by the same scheme. Extraction recovery was evaluated by performing SPE in triplicate on urine samples containing ziprasidone at three concentration levels of the analyte and IS.

Method validation was performed by such characteristics as specificity, accuracy and precision, linearity, repeatability, and matrix effects according to International Conference on Harmonization (ICH) Guidelines (ICH, 2005). An important part of method validation is to determine the indicators of the suitability of the system. To this end, the following parameters were calculated: a number of theoretical plates, peak asymmetry, and repeatability of retention times and peak areas. To prove the specificity of the technique chromatograms of a stock, tested, and placebo solution was compared. Selectivity was studied by analyzing urine samples from several different laboratory rats. The lower limit of quantitation (LLOQ) was defined as the minimal concentration of ziprasidone that can be precisely measured (coefficient of variation (CV) of less than 20\%) and is determined by 5 samples of model tests independent of this curve.
Limit of detection (LOD) was determined by 5 samples of model tests with signal to noise ratio of at least 3:1.

The efficacy of extraction and matrix effects were studied by model samples with three levels of concentrations (low, medium, high). Accuracy and precision of the method were determined by analyzing a series of three solutions with concentrations of 5, 100, $200 \mu \mathrm{g} / \mathrm{ml}(\mathrm{n}=6)$. Samples were analyzed on the day of preparation and 24 hours after preparation (samples were stored at $4^{\circ} \mathrm{C}$ ). Short-term and long-term stability of ziprasidone was studied by model urine samples containing 1 $\mu \mathrm{g} / \mathrm{ml}$ and $200 \mu \mathrm{g} / \mathrm{ml}$ of a drug. Ziprasidone stability during three freeze-thaw cycles was determined as well. $10 \%$ degradation criterion was used to confirm the stability.

\section{RESULTS}

Ziprasidone identification was performed by retention time, which was $9.6 \pm 0.1 \mathrm{~min}$ and by UV spectrum under described analysis conditions. The retention time of internal standard (vardenafil) was $7.6 \pm 0.1 \mathrm{~min}$. The proposed method of extraction and detection of ziprasidone was used to analyze urine samples of laboratory rats that were given the drug under study. Concurrently the results were compared that were obtained after the analysis of model samples of urine containing ziprasidone (Figure 1) and samples of biological fluid of test animals (Figure 2) with blank samples. Most of urine components were eluted from the chromatographic column long before the time of ziprasidone release because no interaction between them was observed. The suggested technique of the extraction of the drug enabled to achieve high efficiency in isolation and purity of samples obtained, as evidenced by minor variations in the zero line in the chromatograms. It was experimentally determined that the ziprasidone recovery from an aqueous solution after solid phase extraction was $97.5-98.2 \%$. The efficiency of extraction of ziprasidonefrom urine was determined by analyzing model urine samples $(n=9)$ with three levels of drug concentrations (low, medium, high).The overall recovery of ziprasidone in the assay was above $95 \%$. Validation parameters of ziprasidone isolation from model urine samples by SPE are presented in Table 1. There is a clear separation of ziprasidone peaks with its metabolites in the chromatograms obtained from urine samples of laboratory rats (Figure 3). Conclusions about the ziprasidone metabolites presence in extracts from the urine of test animals were made comparing the chromatograms of pure urine samples, urine with the standard solution of ziprasidone addition, and urine of animals treated with the drug. We have identified four metabolites observed in all urine samples of the animals treated with ziprasidone and were absent in chromatograms of control urine samples. Their retention time was 9.08, 10.2, 10.75 and $13.43 \mathrm{~min}$. The proposed method enabled to identify mean $46.2 \mu \mathrm{g}$ of ziprasidone in $1 \mathrm{ml}$ of daily urine of animals. The total content of metabolites constituted about $28 \%$ of drug concentration level. The minimum concentration that can be determined in biomaterial is $0.125 \mu \mathrm{g} / \mathrm{ml}$. 


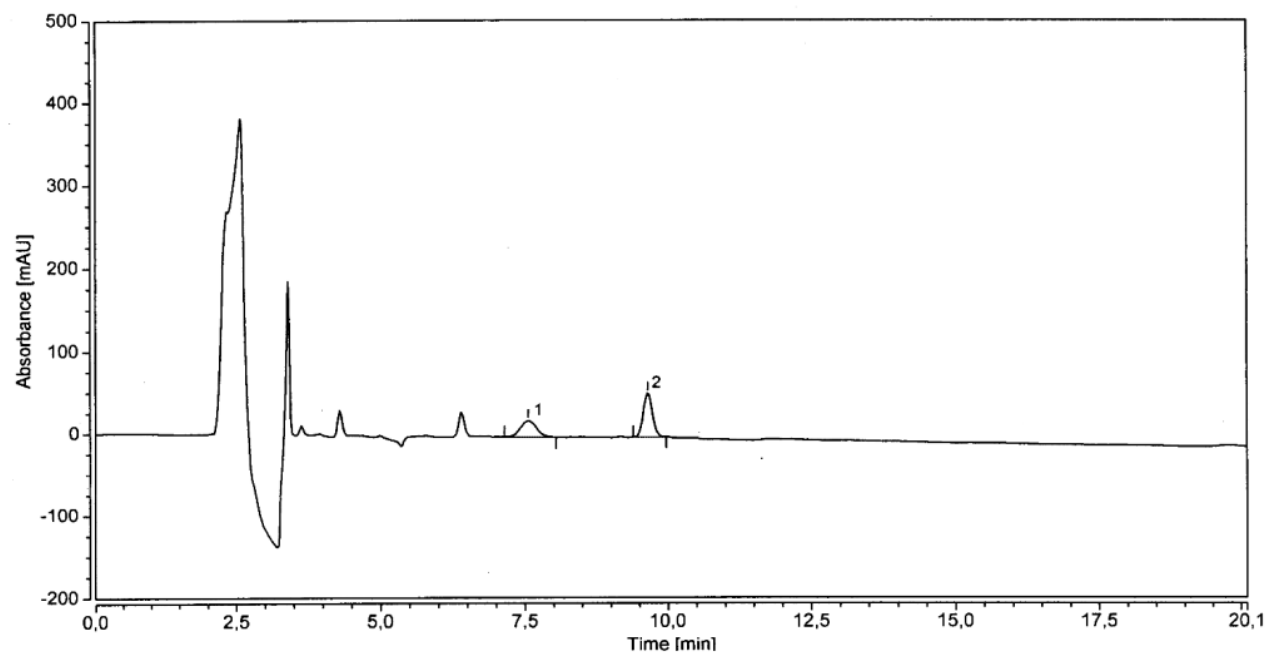

Fig. 1: Chromatograms of model urine samples, containing $30 \mu \mathrm{g} / \mathrm{ml}$ ziprasidone (2) and $10 \mu \mathrm{g} / \mathrm{ml}$ internal standard (1).

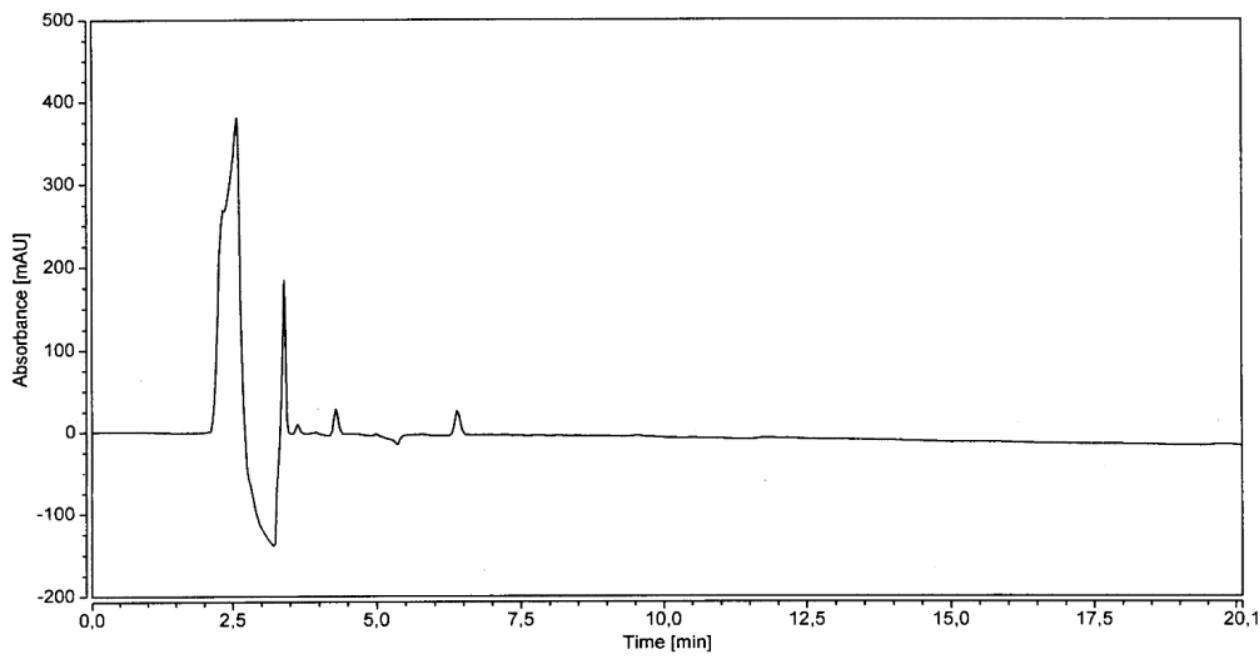

Fig. 2: Chromatogram of drug-free urine samples.

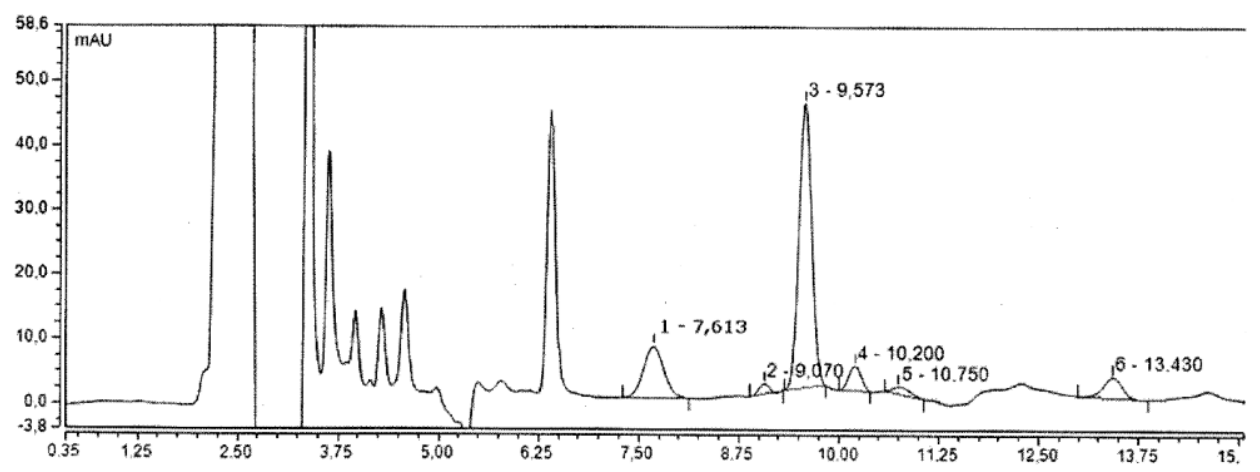

Fig. 3: A representative chromatogram of urine samples of rats treated with ziprasidone. 1 - IS; 3 -Ziprasidone. (Peak area of ziprasidone corresponds to $37 \mu \mathrm{g} / \mathrm{ml}$, and peak area of vardenafil $-10 \mu \mathrm{g} / \mathrm{ml}$.)

Table 1: The extent and efficacy of extraction and matrix effects in the preparation of samples.

\begin{tabular}{ccccc}
\hline $\begin{array}{c}\text { Concentration added } \\
(\boldsymbol{\mu g} / \mathbf{m l})\end{array}$ & $\begin{array}{c}\text { Extraction recovery } \\
(\boldsymbol{\%}) \pm \mathbf{S D}\end{array}$ & $\begin{array}{c}\text { Process efficiency } \\
(\boldsymbol{\%}) \pm \mathbf{S D}\end{array}$ & $\boldsymbol{\%} \mathbf{C V}(\mathbf{R S D})$ & Matrix effect $(\boldsymbol{\%})$ \\
\hline 5 & $95.58 \pm 2.07$ & $95.25 \pm 2.07$ & 2.17 & 100.80 \\
100 & $95.15 \pm 1.85$ & $95.15 \pm 1.85$ & 1.94 & 100.11 \\
200 & $95.08 \pm 1.44$ & $95.05 \pm 1.44$ & 1.51 & 100.17 \\
\hline
\end{tabular}




\section{System suitability}

To study system suitability $10 \mu \mathrm{l}$ of the stock solution of ziprasidone was injected into the chromatograph $(n=6)$ and determined the following parameters: the number of theoretical plates, the number of theoretical plates per meter, coefficient of asymmetry and height equivalent to theoretical plate. Measurement results are presented in Table 2.

The figures in Table 2 confirm high efficacy and selectivity of the proposed system compared to the described before.

The specificity of the proposed method is confirmed by the absence of peaks in the retention time of ziprasidone and its metabolites in chromatograms of control samples of urine.

Table 2: System suitability parameters for ziprasidone.

\begin{tabular}{cc}
\hline Parameters & Values \\
\hline Theoretical Plates $(\mathrm{n})$ & 17112 \\
Theoretical plates per meter (N) & 68448 \\
Height equivalent to theoretical plates [HETP] $(\mathrm{mm})$ & 0.01 \\
Tailing factor & 1.06 \\
\hline
\end{tabular}

\section{Linearity and range.}

The area ratio of ziprasidone peaks to the internal standard in urine samples was linear in relation to the concentration of ziprasidone within $1-30 \mu \mathrm{g} / \mathrm{ml}$ and $30-200 \mu \mathrm{g} / \mathrm{ml}$. In the concentration range of $1-30 \mu \mathrm{g} / \mathrm{ml}$ the calibration graph is described as $Y=0.0827 \times X+0.00313\left(\mathrm{R}^{2}=0.9996\right)$, and in the range of 30 to $200 \mu \mathrm{g} / \mathrm{ml}$, this dependence is $Y=0.05196 \times X+$ $0.75165\left(\mathrm{R}^{2}=0.9988\right)$, where $\mathrm{Y}$ is the area ratio of ziprasidone peaks to the internal standard and $\mathrm{X}$ is the ziprasidone concentration, $\mu \mathrm{g} / \mathrm{ml}$. Results obtained using the calibration graph for model samples of urine are presented in Table 3.

Table 3: Accuracy and precision of the method for determining the concentration of ziprasidone in model urine samples.

\begin{tabular}{|c|c|c|c|c|c|c|}
\hline \multirow[b]{2}{*}{ 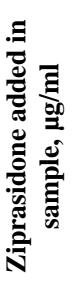 } & \multicolumn{3}{|c|}{ Intra-day $(n=6)$} & \multicolumn{3}{|c|}{ Inter-day $(n=6)$} \\
\hline & 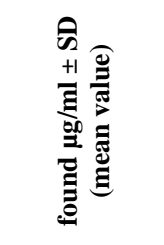 & 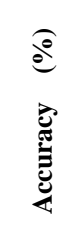 & 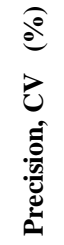 & 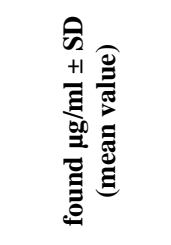 & 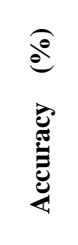 & 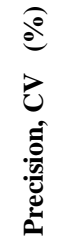 \\
\hline 1 & $0.99 \pm 0.06$ & 99.30 & 6.04 & $0.99 \pm 0.06$ & 99.20 & 6.05 \\
\hline 5 & $4.96 \pm 0.28$ & 99.20 & 5.65 & $4.95 \pm 0.29$ & 99.00 & 5.86 \\
\hline 10 & $9.91 \pm 0.51$ & 99.10 & 5.15 & $9.89 \pm 0.56$ & 98.90 & 5.66 \\
\hline 20 & $19.81 \pm 1.01$ & 99.05 & 5.10 & $19.76 \pm 1.03$ & 98.80 & 5.21 \\
\hline 30 & $29.67 \pm 1.40$ & 98.90 & 4.72 & $29.59 \pm 1.45$ & 98.42 & 4.90 \\
\hline 100 & $98.60 \pm 3.55$ & 98.60 & 3.60 & $98.42 \pm 3.64$ & 98.42 & 3.70 \\
\hline 150 & $147.30 \pm 5.08$ & 98.20 & 3.45 & $146.29 \pm 5.09$ & 97.53 & 3.48 \\
\hline 200 & $195.50 \pm 6.49$ & 97.75 & 3.32 & $192.8 \pm 6.54$ & 96.40 & 3.39 \\
\hline
\end{tabular}

LOD and LOQ were determined by the ratio of signal intensity of analyte to noise signal. Limit of quantitation was set as the lowest concentration that provides the signal/noise ratio above 3:1 for the detection and 5:1 for quantitation. Their values were $0.2 \mu \mathrm{g} / \mathrm{ml}$ and $0.5 \mu \mathrm{g} / \mathrm{ml}$ in methanol solution, respectively.

\section{Accuracy and precision}

Results to determine the accuracy and precision of the HPLC method were within acceptable limits. The results presented in Table 2 show that the method is correct and reproducible for repeated tests of ziprasidone in urine within one day and on different days.

\section{Stability}

Stock solutions of ziprasidone maintained stability for at least 1 month when stored at $4^{\circ} \mathrm{C}$. Model urine samples with ziprasidone maintained stability at $-60 \pm 5^{\circ} \mathrm{C}$. Three freeze-thaw cycles of model urine samples and storage at room temperature for 18 hours demonstrated the stability of ziprasidone in urine. When testing ziprasidone stability the loss of the drug does not exceed acceptable limits when stored in autosampler for 72 hours. The research results are summarized in Table 4.

Table 4: Stability of ziprasidone in urine.

\begin{tabular}{cccc} 
Table 4: Stability of ziprasidone in urine. & & \\
\hline $\begin{array}{c}\text { Storage conditions of } \\
\text { samples }\end{array}$ & $\begin{array}{c}\text { Concentration } \\
\text { of ziprasidone } \\
\text { in the sample } \\
(\boldsymbol{\mu g} / \mathbf{m l})\end{array}$ & $\begin{array}{c}\text { Found } \\
\text { concentration } \\
(\boldsymbol{\mu g} / \mathbf{m l})\end{array}$ & $\begin{array}{c}\% \\
\text { changes }\end{array}$ \\
\hline $\begin{array}{c}\text { Three freeze-thaw cycles } \\
\text { cycles }\left(-20^{\circ} \mathrm{C} / \text { room }\right. \\
\text { temperature) }\end{array}$ & 1.00 & 0.982 & -1.80 \\
\hline $\begin{array}{c}\text { Storage at room } \\
\text { temperature for 18 hours }\end{array}$ & 200.00 & 197.200 & -1.40 \\
\hline $\begin{array}{c}\text { Stability when stored in } \\
\text { autosampler for 72 hours }\end{array}$ & 1.00 & 0.955 & -4.50 \\
\hline $\begin{array}{c}\text { Prolonged storage of urine } \\
\text { samples with ziprasidone } \\
\text { for 60 days }\end{array}$ & 1.00 & 191.800 & -4.10 \\
\hline
\end{tabular}

\section{DISCUSSION}

The primary purpose of this study was to develop a simple, rapid, accurate, and sensitive technique for sample preparation to quantify ziprasidone in urine using the HPLC/UV. It was found that content of ziprasidone in the daily urine of test animals was about $0.67 \%$; the total percentage of identified metabolites in relation to ziprasidone concentration was approximately $28 \%$.

The results from this study showed thatSPE allowed to eliminate the influence of endogenous contaminants from biological fluids and to concentrate the sample, which in turn provided the ziprasidone determination limit in the biological material at the level of $0.125 \mu \mathrm{g}$ in $1 \mathrm{ml}$ of urine. The suggested analysis technique enables to determine both therapeutic and toxic doses of ziprasidone providing an accurate determination of concentrations of the drug in the urine sample to confirm the poisoning or fatality. The described methods of isolation and identification of ziprasidone from urine samples would be suitable for the purpose of post-mortem toxicological investigation.

\section{CONCLUSIONS}

The simple and quick method to determine ziprasidone in the urine of white rats by HPLC/UV in reverse phase column 
LUNA $^{\circledR} \mathrm{C} 18(2)$ was described. The suggested conditions of chromatographic analysis provide rapid extraction of ziprasidone with the matrix components and metabolites, as well as high selectivity, reproducibility and asymmetry of peaks. The results of method validation showed good precision, accuracy and reproducibility. The method maintains linearity in a much larger concentration range than is usually described in the studies making it suitable for chemical and toxicological analysis.

\section{Financial support and sponsorship: Nil.}

Conflict of Interests: The authors' declare no conflict of interest.

\section{REFERENCES}

Asif M. Antipsychotic agents: pharmacological activities of compounds containing arylpiperazines. International Journal of Current Research in Applied Chemistry \& Chemical Engineering, 2016; 2.1:1-30.

Beach SR, Celano CM, Noseworthy PA, Januzzi JL, Huffman JC. QTc prolongation, torsades de pointes, and psychotropic medications. Psychosomatics, 2013; 54.1:1-13.

García M, Ortuño JA., Cuartero M, Abuherba MS.Use of a new ziprasidone-selective electrode in mixed solvents and its application in the analysis of pharmaceuticals and biological fluids. Sensors, 2011; 11.9:8813-8825.

Hasnain M, Vieweg WVR. QTc interval prolongation and torsade de pointes associated with second-generation antipsychotics and antidepressants: a comprehensive review. CNS drugs, 2014; 28.10:887920.

HovdaLR, Brutlag, AG, Poppenga RH, Peterson KL. Atypical Antipsychotics. Blackwell's Five-Minute Veterinary Consult Clinical Companion: Small Animal Toxicology, 2016; 137.

International Conference on Harmonisation (ICH), 2005. Harmonised Tripartite Guideline: Validation of Analytical Procedures: Methodology (Q2B), 2005.

Lee SH, Kim HR, Han RX, Oqani RK, Jin DI. (2013). Cardiovascular risk assessment of atypical antipsychotic drugs in a zebrafish model. Journal of Applied Toxicology, 2013; 33.6:466-470.

Leonard CE, Freeman CP, Newcomb CW, Bilker WB, Kimmel SE, Strom BL, Hennessy S. Antipsychotics and the risks of sudden cardiac death and all-cause death: cohort studies in Medicaid and dually-eligible Medicaid-Medicare beneficiaries of five states. Journal of clinical \& experimental cardiology, 2013; 10.6:1-9.

Levine M, Ruha AM. Overdose of Atypical Antipsychotics. CNS drugs, 2012; 26.7:601-611.

Marano G, Traversi G, Romagnoli E, Catalano V, Lotrionte M, Abbate A., Biondi-Zoccai; Mazza M. Cardiologic side effects of psychotropic drugs. Journal of Geriatric Cardiology, 2011; 8.4:243-253.

Marghade S, Musmade PB, Moorkoth S. High-performance liquid chromatographic assay for ziprasidone in plasma samples: application to pharmacokinetic studies in rats. Journal of chromatographic science, 2012

Mercolini L, Fulgenzi G, Melis M, Boncompagni G, Albers LJ, Raggi MA.Therapeutic drug monitoring (TDM) of the recent antipsychotic ziprasidone in dried blood spots (DBS) and plasma. Pharmacopsychiatry, 2011; 21.06:A21.

Mercolini L, Protti M, Fulgenzi G, Mandrioli R, Ghedini N, Conca A, Raggi MA. A fast and feasible microextraction by packed sorbent (MEPS) procedure for HPLC analysis of the atypical antipsychotic ziprasidone in human plasma. Journal of pharmaceutical and biomedical analysis, 2014; 88:467-471.

Pfizer Inc. FDA Psychopharmacological Drugs Advisory Committee 19 July 2000: Briefing document for Zeldox ${ }^{\circledR}$ capsules (Ziprasidone $\mathrm{HCl}$ ) (online). Available at https://www.fda.gov/ohrms/dockets/ac/00/backgrd/3619b1a.pdf. [Accessed 20 February 2017].
Pfizer Inc. ZELDOX® (ziprasidone hydrochloride) capsules 20, 40, 60, and $80 \mathrm{mg}$ - Product Monograph. Kirkland, Quebec, Canada, 2014. Available http://www.pfizer.ca/sites/g/files/g10017036/f/201411/Clean\%284\%29.pd f. [Accessed 20 February 2017].

Rao KS, Keshar NK., Choudhury PR, Rao MB, Pattnaik AK. RP-HPLC method for the estimation of ziprasidone. Inernational Journal of Pharma Medicines \& Biological Sciences, 2013; 2.1:45-52.

Sampedro MC, Unceta N, Gómez-Caballero A, Callado LF, Morentin B, Goicolea MA, Meana JJ, Barrio RJ. Screening and quantification of antipsychotic drugs in human brain tissue by liquid chromatography-tandem mass spectrometry: Application to postmortem diagnostics of forensic interest. Forensic science international, 2012; 219.1:172-178.

Scott KS. The use of hair as a toxicological tool in DFC casework. Science \& Justice, 2009; 49.4: 250-253.

Shin KJ, Malone TD, Crosby TI, Capuano B.Schizophrenia: a systematic review of the disease state, current therapeutics and their molecular mechanisms of action. Current medicinal chemistry, 2011; 18.9: 1380-1404.

SistikP, UrinovskaR, BrozmanovaH, KacirovaI, SilhanP, Lemr K. Fast simultaneous LC/MS/MS determination of 10 active compounds in human serum for therapeutic drug monitoring in psychiatric medication. Biomedical Chromatography, 2016; 30.2:217-224.

Söderberg C., Wernvik E., Tillmar A., Spigset O., Kronstrand R., Reis M., Druid H. Antipsychotics - Postmortem fatal and non-fatal reference concentrations. Forensic science international, 2016; 266: 91101.

Sreedasyam R, AkulaThukaram B, Khagga M, Dendhi CR. Sensitive LC-MS/MS Method for the Determination of Ziprasidone in Human Plasma and its Pharmacokinetic Application. International Journal of Chemical and Analytical Science, 2012; 3.6:1439-1445.

Strom BL, Eng SM, Faich G, Reynolds RF, D'Agostino RB, Ruskin J, Kane JM. Comparative mortality associated with ziprasidone and olanzapine in real-world use among 18,154 patients with schizophrenia: the Ziprasidone Observational Study of Cardiac Outcomes (ZODIAC). American Journal of Psychiatry, 2011; 168.2:193-201.

Timour Q, Frassati D, Descotes J, Chevalier P, Christé G, Chahine M. Sudden death of cardiac origin and psychotropic drugs. Frontiers in Pharmacology, 2012; 3.76:1-9.

Wang ST, Li Y. Development of an UPLC-MS/MS method for routine therapeutic drug monitoring of aripiprazole, amisulpride, olanzapine, paliperidone and ziprasidone with a discussion of their therapeutic reference ranges for Chinese patients. Biomedical chromatography: BMC, 2017; doi: 10.1002/bmc.3928.

Wenzel-Seifert K, Wittmann M, Haen E. QTc prolongation by psychotropic drugs and the risk of Torsade de Pointes. Dtsch Arztebl Int, 2011; 108.41:687-693.

Xie C. 2014. Ziprasidone. In: Lee PW, ed; Aizawa H, ed; Gan LL, ed; Prakash C, ed. Handbook of Metabolic Pathways of Xenobiotics. First Edition: John Willey \& Sons, Ltd 1-7.

\section{How to cite this article:}

Davydovych S, Halkevych I, Korobova O, Humenyuk S. Solidphase extraction for RP-HPLC/UV determination of ziprasidone at presence its main metabolite in urine. J App Pharm Sci, 2017; 7 (05): 001-006. 